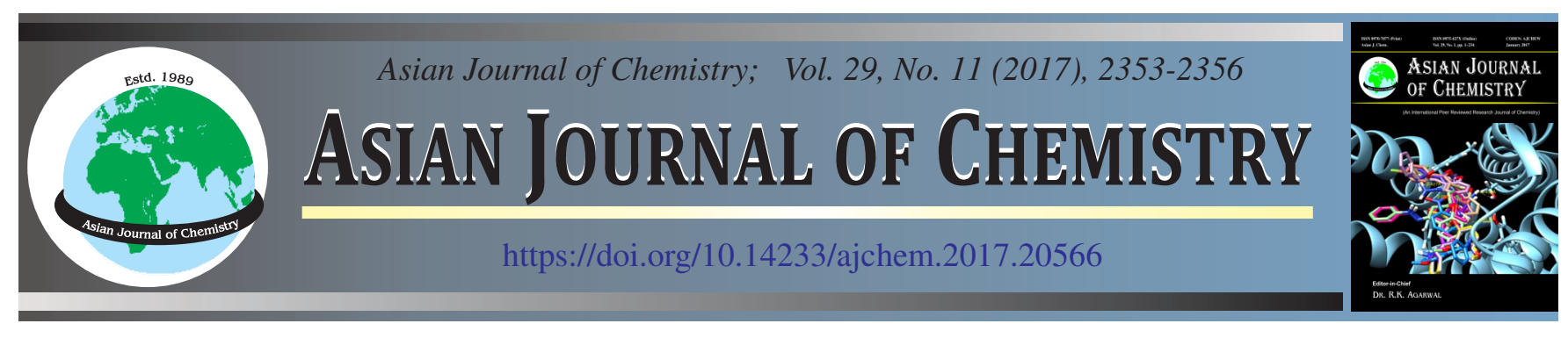

\title{
Spectroscopic Study on Kinetics of Oxidation of Doxycycline Hydrochloride by N-Chlorosuccinamide in Acidic Medium
}

\author{
Vidiavati Shastry ${ }^{1, *}$, P.K. Asha ${ }^{2}$ and B.C. Sateesh ${ }^{3}$
}

\begin{abstract}
${ }^{1}$ Department of Chemistry, South East Asian College of Engineering \& Technology, Bangalore-560 049, India
${ }^{2}$ Department of Chemistry, New Horizon College of Engineering, Bangalore-560 103, India

${ }^{3}$ Department of Chemistry, Shri Pillappa College of Engineering, Bangalore-560 089, India

*Corresponding author: E-mail: vidyavati_kinetic@yahoo.co.in
\end{abstract}

Received: 3 February 2017

Accepted: 28 July 2017;

Published online: 29 September 2017;

AJC-18548

\begin{abstract}
A tetracycline antibiotic doxycycline hydrochloride (DOX) has been oxidized by N-chlorosuccinamide (NCS) in sulphuric acid medium at $303 \mathrm{~K}$ and the kinetics have been investigated. The stoichiometry of the reaction was found to be 1:1 where one mole doxycycline reacted with one mole of NCS and the product of oxidation of doxycycline, 1,4,4a,5,5a,6,11,12a-octahydro-3,5,10,12,12a-pentahydroxy6-methyl-1,4,11-trioxotetracene-2-carboxamide is identified by the spot tests and confirmed by LC-MS spectral analysis. The titled reaction exhibited first-order kinetics with reference to concentration of NCS and doxycycline a fractional order kinetics was observed with respect to $\left[\mathrm{H}_{2} \mathrm{SO}_{4}\right]$ and doxycycline. The changes in the reaction rate on the addition of halide ions and reduction product was studied. The influence of added product, $p$-toluene sulfonamide was studied and found no significant effect. The influence of ionic strength $\left(\mathrm{NaClO}_{4}\right)$ and dielectric constant of the medium was investigated on the reaction rate. All the experimental values were compiled together and a mechanism was proposed. The temperature effect was studied for calculating the activation parameters with reference to the rate determining step in the mechanism and the thermodynamic parameters were also discussed.
\end{abstract}

Keywords: Doxycycline hydrochloride, Kinetics, N-Chlorosuccinamide, Oxidation.

\section{INTRODUCTION}

Doxycycline hydrochloride [IUPAC name: $(4 \mathrm{~S}, 4 \mathrm{aR}, 5 \mathrm{~S}$, 5aR,6R,12aR)-4-(dimethylamino)-1,5,10,11,12a-pentahydroxy6-methyl-3,12-dioxo-4a,5,5a,6-tetrahydro-4H-tetracene-2carboxamide], is a tetracycline derivative used as an antibiotic. It is used to cure Lyme disease, respiratory tract infections, genito-urinary tract infections, severe acne, rickettsial diseases, and eye infections. Doxycycline hydrochloride (DOX) is used for treatment of traveler's diarrhea and other microorganisms sensitive to tetracycline [1-5]. Common side effects of doxycycline hydrochloride are skin rash or mouth sores, rectal itching or soreness, vaginal itching or discharge, or diarrhea occur also make sensitive to sunlight, sensation of nausea and vomiting.

$\mathrm{N}$-halogen compounds are known to be great oxidizing agent [6]. Chlorination and oxidation done with the help of $\mathrm{N}$-Chlorosuccinamide is significant which makes it a versatile reagent [7]. It carries as oxidizing agent in both acidic and alkaline media [5,6,8-16]. Various electrophilic reaction and radical reaction are undergone by it. Formation of carbon-carbon bonds, rearrangements and functional group transformations are controlled by NCS. N-chlorosuccinamide (NCS) have been<smiles>CC1OC2C(=C(O)C3(O)C(=O)C(C(N)=O)=C(O)C(N(C)C)C23)C(=O)c2c(O)cccc21</smiles>

Structure of doxycycline

used for the oxidation study of various alcohol, thiosemicarbazide, amines, aromatic aldehyde as reported in literature [11,13,14].

According to the literature, there is no data accessible on the oxidation of doxycycline with N-chlorosuccinamide (NCS). In order to study, the degradation of doxycycline in environment and also to study the effect of NCS on doxycycline in sulphuric acid medium and to understand the oxidation mechanism, the kinetics of oxidation of doxycycline with $\mathrm{NCS}$ in $\mathrm{H}_{2} \mathrm{SO}_{4}$ medium at $303 \mathrm{~K}$ are perfomed.

\section{EXPERIMENTAL}

Analytical pure doxycycline hydrochloride, the substrate is utilized as received. Aqueous solution of the substrate of the required strength was prepared freshly every time whenever 
required. An aqueous solution of oxidant $\mathrm{N}$-chlorosuccinamide (NCS) (Aldrich) was prepared afresh, standardized by iodometric method using thiosulphate and protected in dark coloured containers to keep any of its photochemical impacts. Doubly distilled water was used all through the work.

Kinetic measurements: The pseudo-first order condition was retained by keeping [DOX] $\gg>$ [NCS]. Glass stoppered pyrex boiling tubes, which was coated black was used to carry out the reactions. The external surface was covered dark to dispose of photochemical impacts. Required amounts of Nchlorosuccinamide (NCS) and $\mathrm{H}_{2} \mathrm{SO}_{4}$ were taken in the pyrex tube and kept in an electrically operated thermostat. Temperature was maintained at $30^{\circ} \mathrm{C}$ for thermal equilibrium. A known volume of solution of NCS also equilibrated thermally at the same temperature and was speedily added to the reaction mixture containing the substrate and maintained acidic medium. The kinetics of the reaction was trailed by assessing a known aliquot of the reaction mixture at different time intervals, iodometrically, using starch as indicator. The pseudo-first order rate constants $(\mathrm{k})$ figured were reproducible inside $\pm 3 \%$.

Stoichiometry and analysis of product formed: The stoichiometry for the oxidation reaction between DOX and NCS was determined with various proportions of NCS and DOX in the presence of $\mathrm{H}_{2} \mathrm{SO}_{4}$. The reaction were equilibrated at $303 \mathrm{~K}$ for $24 \mathrm{~h}$. The results of estimation of unreacted NCS indicated 1:1 stoichiometry i.e., one mole of doxycycline hydrochloride consumed one mole of NCS. The main product of DOX oxidation, 1,4,4a,5,5a,6,11,12a-octahydro-3,5,10,12,12apentahydroxy-6-methyl-1,4,11-trioxotetracene-2-carboxamide is identified by the spot tests [17]. Further, the oxidation product was confirmed by LC-MS spectral analysis. LC-MS analysis of oxidation product of DOX gave a molecular ion peak at $\mathrm{m} / \mathrm{z}$ $=415$ (Fig. 1). The reduction product succinimide was recognized by methods reported elsewhere [18]. The chloride ions were removed by passing the residual solution through column containing anion ion-exchange resin. After the removal of succinimide, the final elute was concentrated to $30 \%$ and the amount obtained was stoichiometric with the concentration of DOX used for the reaction.

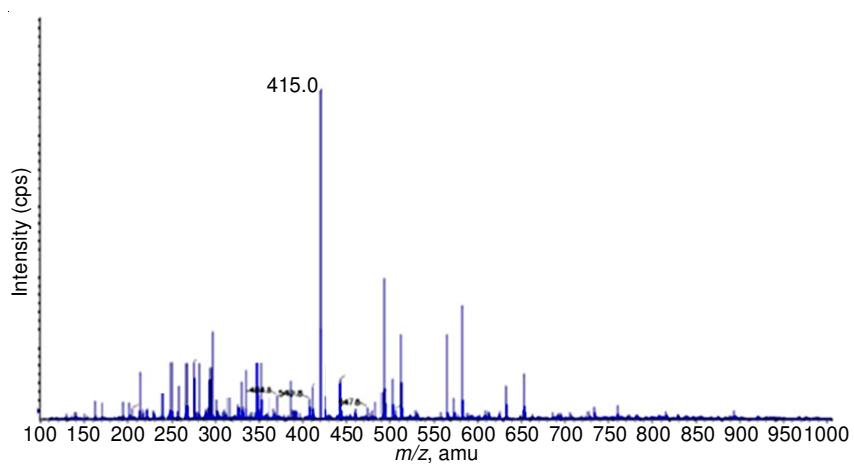

Fig. 1. LC-MS spectra of oxidation product of DOX with NCS (1,4,4a,5,5a, 6,11,12a-octahydro-3,5,10,12,12a-pentahydroxy- 6-methyl-1,4,1,1trioxotetracene-2-carboxamide)

\section{RESULTS AND DISCUSSION}

The oxidation of doxycycline hydrochloride (DOX) under various conditions were examined at different groupings of the reactants in aqueous acidic medium.
Effect of N-chlorosuccinamide (NCS): Kinetics of oxidation of DOX $\left[1 \times 10^{-2} \mathrm{~mol} / \mathrm{dm}^{3}\right]$ by the oxidant NCS, at constant concentration of $\mathrm{H}_{2} \mathrm{SO}_{4}\left[1.2 \mathrm{~mol} / \mathrm{dm}^{3}\right]$ was performed at various initial concentrations of NCS $\left[0.2 \times 10^{-3} \mathrm{~mol} / \mathrm{dm}^{3}\right.$ to $\left.1.4 \times 10^{-3} \mathrm{~mol} / \mathrm{dm}^{3}\right]$ at $303 \mathrm{~K}$ (Table-1). Plots of $\log$ [NCS] versus time are linear having a slope of 1 , which indicates a first order dependence of rate on [oxidant].

\section{TABLE-1}

VARIATION OF CONCENTRATIONS OF DOXYCYCLINE, NCS, $\mathrm{H}_{2} \mathrm{SO}_{4}$ ON THE RATE OF OXIDATION OF DOXYCYCLINE BY N-CHLOROSUCCINAMIDE IN SULPHURIC ACID MEDIUM

\begin{tabular}{ccccc}
\hline $\begin{array}{c}10^{2} \times \\
{[\mathrm{DOX}]} \\
\left(\mathrm{mol} / \mathrm{dm}^{3}\right)\end{array}$ & $\begin{array}{c}10^{3} \times \\
{[\mathrm{NCS}]} \\
\left(\mathrm{mol} / \mathrm{dm}^{3}\right)\end{array}$ & $\begin{array}{c}{\left[\mathrm{H}_{2} \mathrm{SO}_{4}\right]} \\
\left(\mathrm{mol} / \mathrm{dm}^{3}\right)\end{array}$ & $\begin{array}{c}\mathrm{k}_{\mathrm{obs}} \times 10^{-2} \\
\left(\mathrm{~s}^{-1}\right)\end{array}$ & $\begin{array}{c}\mathrm{k}_{\text {cal }} \times 10^{-2} \\
\left(\mathrm{~s}^{-1}\right)\end{array}$ \\
\hline 0.2 & 1 & 1.2 & 1.5 & 0.50 \\
0.6 & 1 & 1.2 & 2.0 & 1.63 \\
1 & 1 & 1.2 & 2.5 & 2.74 \\
1.2 & 1 & 1.2 & 3.5 & 3.27 \\
1.4 & 1 & 1.2 & 4.0 & 3.80 \\
1 & 0.2 & 1.2 & 2.3 & 2.74 \\
1 & 0.6 & 1.2 & 2.5 & 2.74 \\
1 & 1 & 1.2 & 2.5 & 2.74 \\
1 & 1.2 & 1.2 & 2.8 & 2.74 \\
1 & 1.4 & 1.2 & 2.9 & 2.74 \\
1 & 1 & 0.7 & 2.0 & 2.73 \\
1 & 1 & 0.9 & 2.5 & 2.73 \\
1 & 1 & 1.2 & 2.8 & 2.74 \\
1 & 1 & 1.5 & 3.0 & 2.72 \\
\hline
\end{tabular}

Effect of doxycycline hydrochloride (DOX): To study the effect of substrate, oxidation was performed with various concentrations $\left[0.2 \times 10^{-2} \mathrm{~mol} / \mathrm{dm}^{3}\right.$ to $\left.1.4 \times 10^{-2} \mathrm{~mol} / \mathrm{dm}^{3}\right]$ of DOX by using $\left[1 \times 10^{-3} \mathrm{~mol} / \mathrm{dm}^{3}\right] \mathrm{NCS}$ in $\left[1.2 \mathrm{~mol} / \mathrm{dm}^{3}\right] \mathrm{H}_{2} \mathrm{SO}_{4}$ (Table-1). Plots of $\log \mathrm{k}_{\mathrm{obs}}$ versus $\log$ [DOX], where linear with a slope 0.60 , indicating a fractional dependence on [DOX] (Fig. 2).

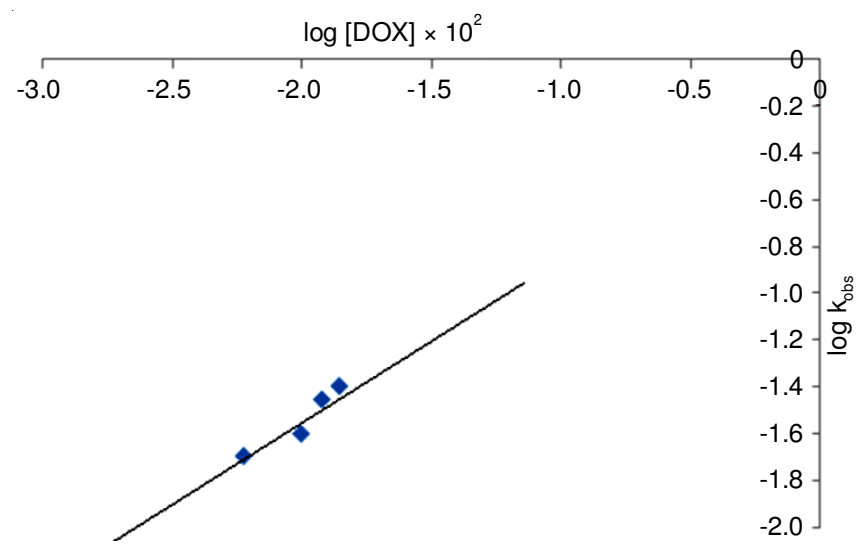

Fig. 2. Plot of $\log \mathrm{k}_{\mathrm{obs}}$ versus $\log [\mathrm{DOX}]$ shows fractional order dependence with respect to doxycycline

Effect of $\mathrm{H}_{2} \mathrm{SO}_{4}$ : The reaction was carried out with $[1 \times$ $\left.10^{-2} \mathrm{~mol} / \mathrm{dm}^{3}\right]$ DOX and $\left[1 \times 10^{-3} \mathrm{~mol} / \mathrm{dm}^{3}\right] \mathrm{NCS}$ at four different concentrations $\left[0.7 \mathrm{~mol} / \mathrm{dm}^{3}-1.5 \mathrm{~mol} / \mathrm{dm}^{3}\right]$ of $\mathrm{H}_{2} \mathrm{SO}_{4}$ at $303 \mathrm{~K}$ (Table-1). A graph plotted between $\log \mathrm{k}_{\mathrm{obs}}$ and $\log$ $\left[\mathrm{H}_{2} \mathrm{SO}_{4}\right]$ was found to be linear with slope of 0.83 , which indicates a fractional order dependence on $\left[\mathrm{H}_{2} \mathrm{SO}_{4}\right]$ (Fig. 3). 


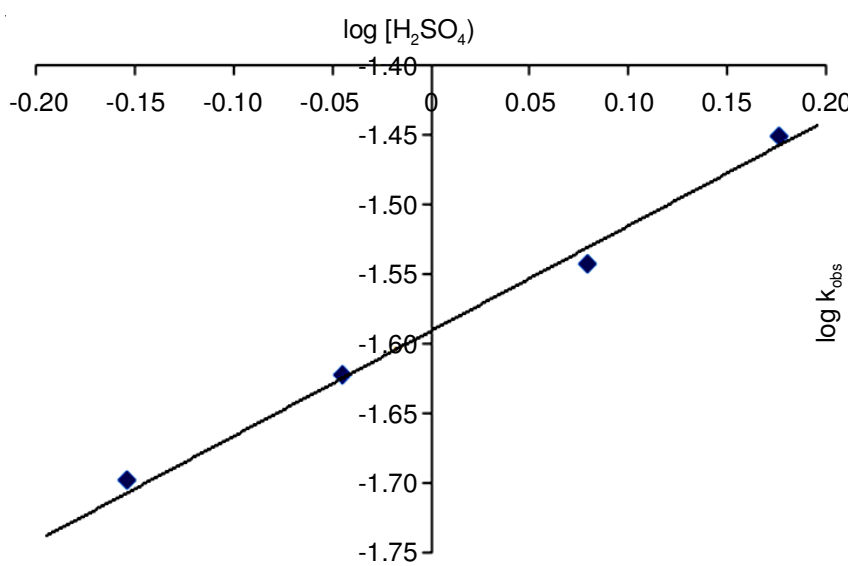

Fig. 3. Graph of $\log \mathrm{k}_{\mathrm{obs}}$ versus $\log \left[\mathrm{H}_{2} \mathrm{SO}_{4}\right]$ shows fractional order dependence with respect to sulphuric acid

Effect of product: The influence of added product succinamide on the rate of reaction was studied by varying the concentration from $1 \times 10^{-3} \mathrm{M}$ to $10 \times 10^{-3} \mathrm{M}$ and found to have no effect on the reaction rate.

Effect of temperature: The rate constant for the oxidation of DOX with NCS at different temperature ranges (303-333 $\mathrm{K}$ ) was measured by keeping the other experimental conditions and reactant concentrations constant. It was noted that the rate constant of the reaction showed a proportional increase with increase in temperature for [DOX] (Table-2). Arrhenius plot of $\log \mathrm{k}$ versus $1 / \mathrm{T}$ gave the activation parameters to characterize the oxidation of DOX using NCS in an acidic medium [19] (Table-3, Fig. 4). The graphical value of $\mathrm{E}_{\mathrm{a}}$ was found to be 74 $\mathrm{kJ} / \mathrm{mol}$ and a negative value $(-46 \mathrm{~J} / \mathrm{K} / \mathrm{mol})$ was obtained for entropy of activation.

\begin{tabular}{|c|c|}
\hline \multicolumn{2}{|c|}{$\begin{array}{c}\text { TABLE-2 } \\
\text { EFFECT OF TEMPERATURE ON OXIDATION } \\
\text { OF DOXYCYCLINE HYDROCHLORIDE BY } \\
\text { N-CHLOROSUCCINAMIDE IN ACIDIC MEDIUM }\end{array}$} \\
\hline Temperature (K) & $\mathrm{k} \times 10^{-2}\left(\mathrm{~s}^{-1}\right)$ \\
\hline 303 & 2.74 \\
\hline 313 & 5.1 \\
\hline 323 & 9.3 \\
\hline 333 & 16.5 \\
\hline
\end{tabular}

\begin{tabular}{|c|c|}
\hline \multicolumn{2}{|c|}{$\begin{array}{c}\text { TABLE-3 } \\
\text { VALUES FOR ACTIVATION PARAMETERS AND } \\
\text { THERMODYNAMIC QUANTITIES FOR THE OXIDATION } \\
\text { OF DOXYCYCLINE HYDROCHLORIDE BY ACIDIC } \\
\text { N-CHLOROSUCCINAMIDE }\end{array}$} \\
\hline Activation parameters & Values \\
\hline $\mathrm{E}_{\mathrm{a}}(\mathrm{kJ} / \mathrm{mol})$ & $74 \pm 3$ \\
\hline$\Delta \mathrm{H}^{\#}(\mathrm{~kJ} / \mathrm{K} / \mathrm{mol})$ & $70 \pm 4$ \\
\hline$\Delta \mathrm{S}^{\#}(\mathrm{~J} / \mathrm{K} / \mathrm{mol})$ & $-46 \pm 3$ \\
\hline$\Delta \mathrm{G}^{\#}(\mathrm{~kJ} / \mathrm{mol})$ & $84 \pm 2$ \\
\hline
\end{tabular}

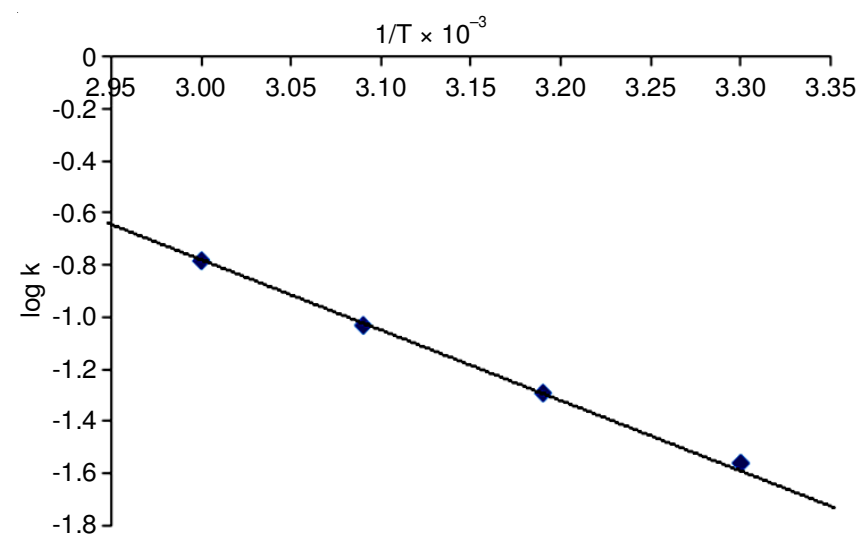

Fig. 5. Impact of temperature on oxidation of doxycycline hydrochloride by $\mathrm{N}$-chlorosuccinamide in acidic medium

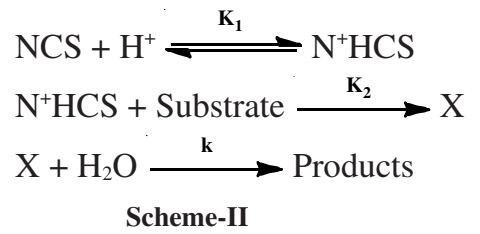

By considering the Scheme-II, rate law can be proposed as follows:

$$
\begin{aligned}
& \text { Rate }=\mathrm{K}_{2}\left[\mathrm{~N}^{+} \mathrm{HCS}\right][\mathrm{S}] \\
& {[\mathrm{NCS}]_{\mathrm{T}}=[\mathrm{NCS}]_{\mathrm{F}}+\left[\mathrm{N}^{+} \mathrm{HCS}\right]} \\
& \mathrm{K}_{1}=\left[\mathrm{N}^{+} \mathrm{HCS}\right] /[\mathrm{NCS}]\left[\mathrm{H}^{+}\right] \\
& {[\mathrm{NCS}]=\left[\mathrm{N}^{+} \mathrm{HCS}\right] / \mathrm{K}_{1}\left[\mathrm{H}^{+}\right]} \\
& {\left[\mathrm{N}^{+} \mathrm{HCS}\right]=\mathrm{K}_{1}\left[\mathrm{H}^{+}\right][\mathrm{NCS}]_{\mathrm{T}} / 1+\mathrm{K}_{1}\left[\mathrm{H}^{+}\right]} \\
& \text {Rate }=\mathrm{K}_{1} \mathrm{~K}_{2}\left[\mathrm{H}^{+}\right][\mathrm{NCS}]_{\mathrm{T}}[\mathrm{S}] / 1+\mathrm{K}_{1}\left[\mathrm{H}^{+}\right] \\
& \mathrm{k}\left[\mathrm{NCS}_{\mathrm{T}}=\mathrm{K}_{1} \mathrm{~K}_{2}\left[\mathrm{H}^{+}\right]\left[\mathrm{NCS}_{\mathrm{T}}[\mathrm{S}] / 1+\mathrm{K}_{1}\left[\mathrm{H}^{+}\right]\right.\right. \\
& \mathrm{k}=\mathrm{K}_{1} \mathrm{~K}_{2}\left[\mathrm{H}^{+}\right][\mathrm{S}] / 1+\mathrm{K}_{1}\left[\mathrm{H}^{+}\right] \\
& \begin{aligned}
1 / \mathrm{k} & =1+\mathrm{K}_{1}\left[\mathrm{H}^{+}\right] / \mathrm{K}_{1} \mathrm{~K}_{2}\left[\mathrm{H}^{+}\right][\mathrm{S}] \\
\quad & =1 / \mathrm{K}_{1} \mathrm{~K}_{2}\left[\mathrm{H}^{+}\right][\mathrm{S}]+\mathrm{K}_{1}\left[\mathrm{H}^{+}\right] / \mathrm{K}_{1} \mathrm{~K}_{2}\left[\mathrm{H}^{+}\right][\mathrm{S}] \\
\quad & =1 / \mathrm{K}_{1} \mathrm{~K}_{2}\left[\mathrm{H}^{+}\right][\mathrm{S}]+1 / \mathrm{K}_{2}[\mathrm{~S}]
\end{aligned}
\end{aligned}
$$

The dynamic oxidizing species must be recognized, before recommending a most likely mechanism. The idea of the dynamic oxidizing species and the mechanism rely upon the idea of the halogen, the group connected to nitrogen and response condition. Under the experimental conditions studied, $\mathrm{HOCl}, \mathrm{N}^{+} \mathrm{HCS}, \mathrm{Cl}_{2}$ and $\mathrm{NCS}$ itself in aqueous solution can be the viable oxidizing species [20]. Chlorine gas can be opted out from the oxidizing species in view of the first order dependence of rate on concentration of NCS. Additionally, if $\mathrm{HOCl}$ is the expected as the reactive species, a first order retardation of rate by succinimide is expected. As these are not observed, the effective oxidizing species in the rate deciding step zeroes down to conjugate acid $\left(\mathrm{N}^{+} \mathrm{HCS}\right)$ in acidic solution of NCS in the titled framework. The effect of DOX as experimented was found to be fractional order, which

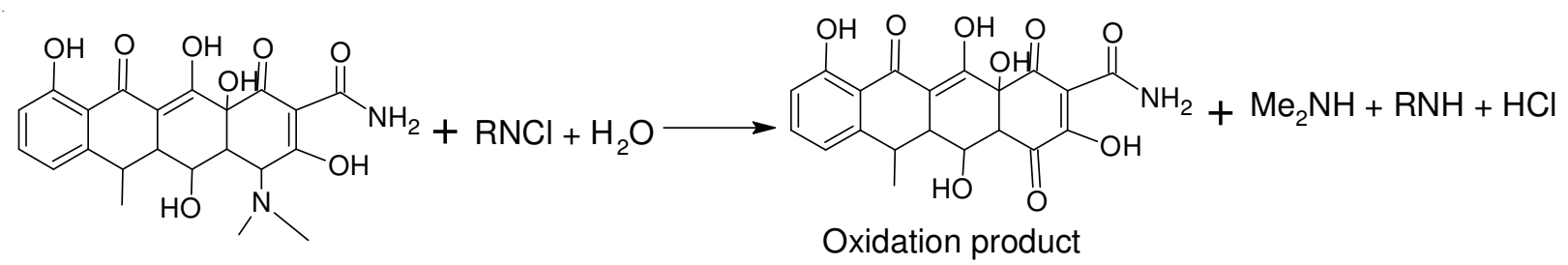


obviously showed complex development between the oxidant and substrate in an equilibrium step before the rate limiting step. However, the rate dependence on $\left[\mathrm{H}^{+}\right]$demonstrates the involvement of a neutral species in the rate determining step. The reaction product of NCS, succinimide had no effect on the rate thus indicating that it was not involved in preequilibrium with oxidant. In light of the above certainties, the component of oxidation of DOX by NCS in acid medium is best disclosed by Scheme-II to account all the observed kinetic data. The protonated NCS reacts with the substrate SchemeII to form the intermediate $\mathrm{X}$. The intermediate ' $\mathrm{X}$ ' undergoes hydrolysis to give products.

\section{Conclusion}

The study of oxidation of doxycycline with N-chlorosuccinamide (NCS) in sulphuric acid medium has been investigated. The reactive species of NCS was observed to be $\mathrm{N}^{+} \mathrm{HCS}$. The stoichiometry of the reaction was observed to be 1:1 and the oxidation items were recognized by spot test and LC-MS. The higher negative value of $\Delta S^{\#}$ supports the development of complex in reaction. From the above experimental procedure suitable rate law is proposed. The rate law is verified, calculated and observed rate constants are in good agreement.

\section{REFERENCES}

1. R.L. Sweet, J. Schachter, D.V. Landers, M. Ohm-Smith and M.O. Robbie, Am. J. Obstet. Gynecol., 158, 736 (1988); https://doi.org/10.1016/S0002-9378(16)44537-0.

2. H. Gjonnaess and E. Holten, Acta Obstet. Gynecol. Scand., 57, 137 (1978); https://doi.org/10.3109/00016347809155893.

3. M. Maatta, O. Kari, T. Tervahartiala, S. Peltonen, M. Kari, M. Saari and T. Sorsa, Graefes Arch. Clin. Exp. Ophthalmol., 244, 957 (2006); https://doi.org/10.1007/s00417-005-0212-3.

4. M.J. Quarterman, D.W. Johnson, D.C. Abele, J.L. Lesher, D.S. Hull and L.S. Davis, Arch. Dermatol., 133, 49 (1997); https://doi.org/10.1001/archderm.1997.03890370055009.
5. J.-C. Fan, Z.-C. Shang, J. Liang, X.-H. Liu and Y. Liu, J. Phys. Org. Chem., 21, 945 (2008); https://doi.org/10.1002/poc. 1404 .

6. J.S. Yadav, B.V. Subba Reddy, R. Jain and G. Baishya, Tetrahedron Lett., 49, 3015 (2008); https://doi.org/10.1016/i.tetlet.2008.02.136.

7. M.M. Campbell and G. Johnson, Chem. Rev., 78, 65 (1978); https://doi.org/10.1021/cr60311a005.

8. N.S. Srinivasan and N. Venkatasubramanian, Tetrahedron Lett., 30, 419 (1974); https://doi.org/10.1016/S0040-4020(01)97017-6.

9. N.S. Srinivasan and N. Venkatasubramanian, Tetrahedron Lett., 11, 2039 (1970); https://doi.org/10.1016/S0040-4039(01)98147-X.

10. A.H. Haines, Methods for the Oxidation of Organic Compounds, Academic Press Inc., p. 165 (1988).

11. B.T. Gowda and J.I. Bhat, Int. J. Chem. Kinet., 21, 621 (1989); https://doi.org/10.1002/kin.550210803.

12. A. Safavi and M.A. Karimi, Talanta, 57, 491 (2002); https://doi.org/10.1016/S0039-9140(02)00048-6.

13. S.P. Nayak and B.T. Gowda, J. Phys. Org. Chem., 5, 755 (1992); https://doi.org/10.1002/poc.610051108.

14. J.M. Antelo, F. Arce, J. Franco, M.C.G. Lopez, M. Sanchez and A. Varela, Int. J. Chem. Kinet., 20, 397 (1988); https://doi.org/10.1002/kin.550200506.

15. P. Kowalski, K. Mitka, K. Ossowska and Z. Kolarska, Tetrahedron, 61, 1933 (2005); https://doi.org/10.1016/j.tet.2004.11.041.

16. N. Mathiyalagan and R. Sridharan, Indian J. Chem., 44A, 2044 (2005).

17. F. Feigl, Spot Tests in Organic Analysis, Elsevier, Amsterdam, edn 5 (1966).

18. B.T. Gowda, N. Damodara and K. Jyothi, Int. J. Chem. Kinet., 37, 572 (2005); https://doi.org/10.1002/kin.20103.

19. B.C. Sateesh, V.A. Shastry, S. Shashidhar and T.N. Padmini, Int. J. Chem. Pharm. Sci., 6, 77 (2015).

20. N. Nanda, P. Kumar and Malini, Int. J. Pharm. Sci. Rev. Res., 23, 388 (2013). 